\title{
Contra os filhos do Império Celeste: a visão de Angelo Agostini em relação ao imigrante chinês
}

\author{
Against the sons of the Empire Celeste: the vision about chinese \\ immigration according to Angelo Agostini
}

Maysa Silva Oliveira ${ }^{1}$

\begin{abstract}
Resumo: O propósito deste artigo é analisar a visão do italiano Angelo Agostini sobre a hipótese da imigração chinesa no Brasil, por meio de suas charges publicadas na Revista Ilustrada. Mesmo sabendo que o uso da mão de obra dos chineses tinha sido bem-sucedida em países como Cuba, Estados Unidos e Peru, ela ainda era um entrave por aqui. Ainda que poucos chineses tenham vindo para nosso País, essa aceitação ocorria com um fato curioso: ela tinha caráter transitório, ou seja, depois de anos de trabalho, o imigrante do Império Celeste tinha de voltar para casa. Esse caráter transitório parece ter acalmado os nervos de uma elite que tinha como objetivo obter mão de obra barata e branca, pois evitava que eles permanecessem no Brasil. Essa característica discriminatória das elites foi muito discutida, principalmente durante o Congresso Agrícola de 1878, no Rio de Janeiro, A Revista Illustrada, meio de comunicação impresso existente em fins do século XIX, demonstrou a posição de Angelo Agostini acerca do tema. Por isso, teremos como fonte da análise da questão, as charges publicadas nela. A partir de então, teremos uma base concisa para analisarmos os trabalhos de Agostini sob o prisma da imigração asiática.
\end{abstract}

Palavras-chave: Imigração. Chineses. Angelo Agostini.

Abstract: The purpose of this article is to analyze the view of the Italian Angelo Agostini when considering the hypothesis of Chinese immigration. Even knowing that the use of Chinese labor had been successful in countries like Cuba, the United States, and Peru, it was still a hindrance here. Although few Chinese came to our country, this acceptance took place with a curious fact: it was accepted only on a transitional basis, that is, after years of work, the emigrant of the Celestial Empire, had to return home. This transitory character seems to have calmed the nerves of an elite that had as objective to obtain cheap and white labor because it avoided that they remained in Brazil. This characteristic of elites has been reproduced and has been the subject of discriminatory views. In order to try to understand how the Illustrada Magazine, printed means of communication in the period, as sources for the analysis of the question, we will use the cartoons published in it. From then on, we will have a concise basis for analyzing the artist's cartoons under the prism of Asian immigration.

Keywords: Immigration. Chineses. Angelo Agostini. 


\section{Introdução}

O presente trabalho tem como finalidade estudar uma parte do século XIX e as transformações que ocorreram na época, decorridas do fim da mão de obra escrava. Nessa conjuntura, o Brasil ainda era uma sociedade escravista e, por isso, existia uma divisão racial dentro do Império.

Após o endurecimento da Inglaterra quanto à escravidão, o País passou a discutir internamente o que faria com os escravos que seriam libertos. Após a abolição do tráfico de escravos, em 1808, a Inglaterra não demorou a abolir a escravidão de suas próprias colônias no ano de 1834. A partir dessa data, a pressão também chegou ao Brasil.

Embora soubessem que o trabalho escravo terminaria, as elites não conseguiam ver o futuro do país sem essa mão de obra e, muito menos, com a utilização do trabalho assalariado (LESSER, 2015, p. 59).

Segundo Emília Viotti da Costa (1998, p. 19), no início do século XIX, o Brasil contava com, aproximadamente, 1.3 trilhão brancos e 3.9 trilhões de negros e mestiços, escravos ou livres.

Em 1830, a população brasileira, de acordo com Luiz Aranha Corrêa do Lago, era de 5,3 milhões e, em 1850, teria aumentado para cerca de 7 milhões. Já com relação à população escrava, estima que, entre os anos de 1811 e 1850, 1,3 milhão de escravos adentraram o País, podendo ter somado, à época, mais ou menos 2 milhões de habitantes escravos e 5 milhões de livres (DO LAGO, 2014, p. 67-68).

\section{A escravidão no Brasil}

No Brasil, em termos de escravidão, Seymour Drescher (2011), em sua obra intitulada Abolição, nos mostra que, até 1850, o trabalho escravo parecia ser uma instituição muito forte, mesmo que a Inglaterra já tivesse dado as cartas sobre isso. Isso porque, em território nacional, não houve conflito nem difusões ideológicas que ameaçassem modificar o quadro instaurado.

O partido conservador refletia os interesses das elites em continuar a fazer o que já lhes era costumeiro: lucrar com a mão de obra gratuita. Sendo assim, o Brasil insistia em manter todos os escravos ilegais que entrassem em território nacional, de 1830 até 1850, o que dava uma confiança no escravismo aos fazendeiros.

Por outro lado, com as leis que dificultavam cada vez mais o tráfico para as colônias portuguesas, a oferta de mão de obra tornou-se menos frequente e a necessidade de trabalhadores continuou crescente.

O transporte de escravos e o custo de seus subornos, uma vez que a proibição da entrada de negros escravizados estava vigorando, acabavam por elevar o preço do mesmo em pelo menos cinco vezes mais durante o período de 1810 a 1860.

Tal afirmação é corroborada quando notamos que as importações de escravos atingiram seu ápice antes de 1851, data divisora de águas entre a escravidão e o trabalho livre (ELTIS, 1987, Apêndice A).

Mas, a questão que ficava em aberto era a de: quem iria ocupar o lugar dos antigos escravos em uma sociedade com raros casos de trabalhadores assalariados? A primeira das respostas 
já exclui o próprio negro, que agora liberto, já não é visto como uma possibilidade de trabalhador com direito à remuneração.

\section{A mão de obra branca no país}

Jeffrey Lesser (2015) em sua obra A invenção da brasilidade: identidade nacional, etnicidade e políticas de imigração, mostra o apreço da família de Don Pedro I e II pela liberdade em relação à Portugal, e o fato dessa posição ter levado o Brasil a se transformar em Império.

Tendo autonomia, a política brasileira em procurar por imigrantes foi também apoiada pela esposa de Dom Pedro, Maria Leopoldina, de origem austríaca.

Já nas mãos de Dom Pedro II, a busca por emigrantes alemães tornou-se intensa. Mas, para que essa emigração da Europa acontecesse, seria necessário que a imagem do País fosse refeita internacionalmente.

O Brasil tinha uma imagem que não agradava aos europeus, portanto, pessoas e políticas de modificação de imagem foram enviadas para o exterior. O resultado, ainda que pequeno, fora que alguns alemães chegaram ao País, inclusive soldados, o que feria algumas das regras do Congresso de Viena.

Sem dinheiro e sem apoio, a solução do governo brasileiro foi contratar imigrantes para que viessem a trabalhar em sistemas de parceria, nos quais poderiam lucrar com os ganhos da produção. Mas, na verdade, o que houve foi uma nova abertura para que os latifundiários brasileiros começassem a explorar os imigrantes, fato que se propagou até as regiões das quais vinham muitos colonos, gerando preocupação com as condições a que estavam submetidos. As péssimas notícias trouxeram representantes dessas regiões para observar se os rumores eram verdadeiros.

O resultado disso implicou na proibição da imigração para o Brasil durante alguns períodos, como em 1859, momento em que o governo da Prússia, país de emigração em massa para as terras brasileiras, colocou em vigor o Édito de Heydt, proibindo o recrutamento de pessoas.

A preferência pela entrada de trabalhadores brancos era baseada no fato de que o branco seria representante do povo ariano, uma vantagem, pois a raça branca era dada como superior.

Essa corrente, vinda da Europa, tentava explicar o sucesso que os europeus vivenciavam no campo político e econômico. Segundo essa teoria, os povos brancos seriam superiores por sua hereditariedade e eram influenciados pelo clima, ao passo que os povos de regiões tropicais não partilhavam dos mesmos ancestrais e a diferença climática também era um fator que pesava quando o assunto era desenvolvimento político, social e econômico.

Portanto, propagar essa ideia era levar as raças humanas não europeias a serem definidas através de "uma teoria pseudocientífica, mas racionalizada, postulando a inferioridade inata e permanente dos não brancos" (SKIDMORE, p. 65, 1976).

Georges Cuvier, (1817) naturalista, que criou o termo "raças" para enquadrar indivíduos com características genéticas em comum, acabou gerando um certo desconforto frente ao legado religioso que propunha a ascendência única de todos os povos. 
A teoria poligenista, na qual cada povo teria surgido em pontos diferentes e não traziam traços em comum, acabou fomentando a antropometria, por exemplo, que acabava medindo o tamanho craniano de raças distintas e atribuindo a capacidade humana de acordo com as suas proporções (SCHWARCZ, p. 99, 1993).

Assim, essa seleção por brancos teria de ser pura, a fim de formar elementos que pudessem trazer progressos. Tais teorias obtiveram força, e juntamente ao Iluminismo, ganharam a América.

Mas, a questão central, é que nenhum desses imigrantes havia transformado o Brasil racial ou economicamente.

Dessa forma, outro debate passou a ser conduzido pelo cenário político, frente à desconstrução de glórias do povo da Europa Central. Agora, os imigrantes chineses eram cogitados novamente, uma vez que o interesse já surgira antes do Império. A sua entrada era apoiada por nomes ilustres, como o deputado federal Aureliano Candido Tavares Bastos (1839-1875) e pelo presidente do Conselho Imperial e ministro da Agricultura, Comércio e Obras públicas, João Lins Vieira Cansanção de Sinimbu, que se tornaria também primeiro ministro.

No entanto, foram pessoas de alto renome, como o fazendeiro Lacerda Werneck e Karl Von Koseritz (curiosamente, também imigrante, que deixara os campos e montara um editorial na cidade), que levaram, juntamente com outras pessoas, ao ponto final da discussão, quando um rico empresário chinês, Tong-sing, ficou perplexo ao saber das murmurações a respeito de sua raça, encerrando as intenções de fazer negócios com o Brasil.

Também no período, disseminou-se a ideia de que o branco seria superior ao negro, bem como o seu trabalho, reforçando ainda mais a ideia da necessidade de por fim à escravidão e do aumento das correntes imigratórias.

Aqui, retomaremos um pouco da discussão sobre a cor, baseada nas observações de Celia Maria Marinho de Azevedo:

A inferioridade racial em termos biológicos começou a ser atribuída aos africanos principalmente a partir de meados do século XIX, com o início dos experimentos científicos com cérebros humanos e símios e a publicação de tratados sobre as diferenças das raças humanas, bem como suas distintas aptidões naturais. Segundo Winthrop Jordan, no início do século XVIII o conceito de inteligência não incluía uma demarcação entre atributos inerentes e adquiridos e, como havia um abismo cultural entre europeus e africanos, estes últimos, recém-chegados à América (Estados Unidos) e na condição de dominados, pareceram muito estúpidos na perspectiva dos brancos. A partir daí foi simples concluir que os negros eram de uma estupidez inveterada e natural [...] (AZEVEDO, 1987, p. 52).

Apesar da preferência pelo homem branco, a imigração foi permitida a todo e qualquer trabalhador, pois a economia, que sofrera uma queda como reflexo das leis contra a escravidão, passou a ditar as regras, admitindo qualquer mão de obra. 


\section{A imigração chinesa no Brasil}

A entrada de imigrantes, porém, nem sempre resultava na ação esperada de trabalhar nas lavouras e engenhos canavieiros, pois, muitas vezes, eles próprios acabavam por encontrar melhores ofícios.

Sendo assim, já não importava a cor daqueles que viriam, desde que fossem obedientes, trabalhadores e custassem pouco. Então, após o fim da escravidão, os trabalhadores cogitados passaram a ser os índios mexicanos, africanos e asiáticos. Mas, quem seria esse trabalhador livre?

O Brasil, desde 1822, já possuía autonomia, declarada após o quadro da Independência e o fim da utilização forçada da mão de obra de descendência africana, que só ocorreu em 1888, e que culminou em uma nova população livre, mas apresentava uma enorme população recém-liberta que não tinha onde trabalhar, já que, por muitas vezes, o liberto era visto como desocupado, preguiçoso e inconfiável, marginalizando ainda mais a imagem do negro (AZEVEDO, 1987, p. 217-218).

Fernando Novais (1996, p. 46) ressalta que, com o fim da monarquia, o Império passou a contar com uma elite defensora do sistema escravista, mantendo-a subordinada. Dessa forma, para que os interesses desse grupo fossem mantidos, o processo abolicionista foi protelado o máximo possível.

Assim também aponta Seymour Drescher, ao dizer que o Poder Moderador, concentrado na figura de D. Pedro II, nomeava representantes das elites para ocupar funções que esse desejava, mostrando o poder do clientelismo e das redes hierárquicas de influência (DRESCHER, 2011, p. 503).

Para Robert Conrad (1975 apud ZANETI et al., 2008, p. 57), a abolição do tráfico de escravos foi uma das principais medidas contra a escravatura, da mesma forma como assinala Paula Beiguelman (2004, p. 189-219), que soma, a essa mesma linha de pensamento, os jogos políticos e partidários entre os grupos Liberais e Conservadores. Nesta ordem, a historiadora credita a fatos também internos, as decisões sobre o fim da escravidão.

Com o fim do tráfico ilegal e a abolição da escravatura, o preço do escravo acabou então se elevando dentro do País, e a expectativa de usá-los como um seguro entre transações financeiras também se reduziu, já que começaram a ficar escassos.

Assim, a nova garantia entre transações financeiras seriam as terras, a partir da aplicação da Lei de Terras. Essa Lei tinha o objetivo de demarcar as terras públicas para propor a compra delas pelos imigrantes como quesito para atração destes, por óbvio, desde que pudessem comprá-las, gerando lucros ao governo, que seriam investidos na transação entre colonos que não possuíam meios para pagar sua vinda.

Dentro deste aspecto, o colono chinês teve seu destaque.

No Brasil, a imigração de chineses também obedeceu a questão do trabalho sob contrato e a preferência por trabalhadores europeus a princípio.

Vindos do Velho Mundo, os europeus resolveriam dois problemas de uma vez: a falta de trabalhadores no território nacional e, especialmente, no que viria a ser o carro chefe de nossa economia, a lavoura cafeeira e as terras a serem cultivadas, além do clareamento populacional. O branco era, assim, considerado essencial, sendo a salvação nacional, pois retiraria o País do "poço" em que se encontrava. 
Vários homens importantes no cenário nacional, como Menezes e Souza, creditavam, ao imigrante europeu, a árdua tarefa de trazer o dinamismo para a sociedade brasileira.

Apesar da hipótese da implementação de chins acabar rendendo alguns frutos, desde que ela fosse por contrato, esses imigrantes ainda seriam uma das últimas opções para ocupar o trabalho.

Entretanto, um forte embate contra a ideia do trabalhador oriental fora objeto de estudo durante o Congresso Agrícola de 1878, no qual até alguns médicos, entre eles Nicolau Moreira, tiveram o seu peso ao analisar a razão para negar a entrada dos filhos do Império Celeste.

Para Nicolau Moreira, o chinês era inferior e não deveria entrar em solo brasileiro, pois seria inevitável que ele se misturasse, gerando uma "mongolização" no País, acrescentando ainda que o bom cruzamento seria aquele em que o negro se misturava ao branco, na tentativa de civilizar a nação².

Dentro da perspectiva da produção cafeeira, é relevante considerar que o café aumentou seu preço a partir de 1885 e se manteve até 1896, permitindo grandes lucros, índices de expansão e a entrada massiva de europeus. Porém, não devemos reduzir o Brasil a apenas São Paulo, necessitando entender que a falta de trabalhadores assumiu contornos diferentes em outras regiões, chegando, até mesmo, a não ser um grande problema, como em Minas Gerais, por exemplo, já que, por lá, a agricultura não se constituía o grande fator econômico de produção (NARO, 1992, p. 74).

Dentro do quadro instaurado, já em 1854, a questão chinesa teve a sua importância, pois passou a ser cogitada como válida, devido ao sucesso em países como Cuba e Peru (NORTHRUP, 1995, p. 25).

Mas, no ano de 1869, um estudo conduzido por Xavier Pinheiro, sobre as importações dos chins, foi discutido em âmbito parlamentar, arrancando pareceres positivos e negativos.

Também se notou certo receio com relação à entrada desses trabalhadores devido a uma experiência fracassada em 1810, momento em que alguns deles foram trazidos para plantações de chá (LESSER, 2001, p. 41).

Em 1870, a negociação de asiáticos ficou por conta de Manoel da Costa Lima Vianna e João Antônio de Miranda e Silva, que obtiveram exclusividade nas importações (IOTTI, 2001, p. 304-307).

Os números de imigrantes foram abordados por Conrad (1975, p. 41-55), que trouxe algumas estimativas: em 1810, chegaram 500 chineses aproximadamente; em 1856, 360; em 1859 e 1866, 612; em 1874, mil chineses; em 1893, 475 - total de 2.947.

A empreitada, entretanto, não floresceu, e novamente, teorias raciais visavam macular a imagem dos mesmos por meio de argumentos depreciativos, que ficaram claros no Congresso Agrícola de 1878 (CARVALHO, 1988, p. V-X).

De acordo com Maria José Elias (1970, p. 57-100), a questão dos chineses acabou por influenciar a opinião pública e gerou a hipótese de que esse tipo de trabalhador fosse o único que aceitaria trabalhar por tão baixo salário, coisa que o europeu não faria.

\footnotetext{
2 Para uma maior discussão, consultar: LIMA, Silvio Cezar de Souza. Determinismo biológico e imigração chinesa em Nicolau Moreira (18701890). 2005. 123 f. Dissertação (Mestrado em História das Ciências e da Saúde) - Casa de Oswaldo Cruz/Fiocruz, Rio de Janeiro, 2005. 3 Conferir em GONÇALVES, Paulo César. Mercadores de Braços: riqueza e acumulação na organização da emigração europeia para o Novo Mundo. 1. ed. São Paulo: Alameda Casa Editorial/FAPESP, 2012.
} 
Nesse congresso, organizado pelo então ministro da Agricultura, Cansanção de Sinimbú, seriam decididos o futuro do Brasil e a questão "chin", que se tornou um dos principais focos de atenção, sem, no entanto, descartar vários insultos contra a ideia do imigrante amarelo.

Existia, ainda, um discurso que caracterizava os orientais com boas qualidades, o que se permitia perceber a tentativa de alguns interessados na mão de obra amarela, mesmo no papel de trabalhadores "transitórios". Assim, os comparava ao indígena nacional, salientando as suas qualidades (DEZEM, 2005, p. 61-73).

Também é interessante ressaltar que o tratamento ao povo asiático não era dos melhores, chegando-se a compará-los com animais. Podemos ver isso ao analisar a entrada de um grupo de chineses no País, vindos por meio do desejo de Dom Pedro I em aprimorar a produção de chá. No entanto, a empreitada não obteve êxito devido às condições regionais e aos conflitos entre os chineses e os seus superiores. Fato evidenciado por meio do relato que, durante uma fuga de dois chineses, o filho de Dom João os teria caçado com cavalos e cães, além de severa desconfiança por causa dos segredos utilizados nas plantações de chá do Rio de Janeiro (DEZEM, 2005, p. 49).

É dentro desse contexto que analisaremos o trabalho do artista Angelo Agostini. Nascido na cidade de Vercelle, na Itália, logo mudou-se para Paris, estudando em escolas de artes plásticas, e chegando ao Brasil no ano de 1861, com apenas dezoito anos.

Em 1864, Agostini fundou sua primeira revista caricatural, intitulada o Diabo Coxo. Autor de Nhô Quim ou Impressões de uma Viagem à Corte e de histórias que possuem publicações nas revistas Vida Fluminense, O Malho e Dom Quixote, ficou mais conhecido como fundador e redator da Revista Illustrada, em 1876. A revista foi responsável por atribuir ao artista a fama de abolicionista por causa de suas publicações (BALABAN, 2009, p. 18).

Tal análise servirá como base para compreensão de seu trabalho e da sua relação com as políticas vigentes nos períodos de suas publicações, que, de acordo com Hernan Lima, seriam ferramentas importantíssimas para o almejo dos grupos abolicionistas (LIMA,1963, p. 208).

Grande parte de seu trabalho está relacionado com a figura do negro e o processo abolicionista, assim como mostra um trecho escrito de sua própria autoria:

A "Revista Illustrada" de 1876 a 1889 onde tanto combati em favor da abolição, a ponto de perder quasi todos os assignantes do interior e das fazendas e onde deixei Pereira Netto substituir-me, o que fez perfeitamente, e o Don Quixote de 1895 até hoje (DON QUIXOTE, 1903, p. 2-3).

Porém, podemos notar que, apesar de ser considerado um abolicionista, esse rótulo foi dado pouco após os períodos de divulgação das imagens, dando-nos a entender que, durante o momento de publicação, ele não era considerado como um atuante em prol do fim do escravismo.

Apesar de encontrarmos elogios rasgados a sua figura, esses também vieram a calhar um tempo depois, principalmente ao aproximar-se de sua morte. Porém, sua relação com ideários pró-abolição, como Joaquim Nabuco, rendeu-lhe a fama de uma pessoa engajada com a causa humanitária.

Vejamos o trecho abaixo, escrito por José do Patrocínio em 7 de abril de 1888: 
É assim que tratamos a ele, o bom, o grande. Alma sem rugas, não se lhe refolham ódios nem pretensões. Quanto mais cresce, mais se democratiza; quanto mais sofre mais ama. Só lhe conhecemos uma vaidade: a de não ter precisado nascer nessas paragens do Cruzeiro do Sul para ser um dos primeiros, dos mais beneméritos brasileiros. Poeta do Lápis, as suas musas são a justiça, a liberdade e a fraternidade (1888 apud BALABAN, 2009, p. 32).

Entretanto, esses ideais de Justiça, liberdade e fraternidade não impedem que percebamos certa sátira nas produções de Angelo Agostini.

Porém, não será apenas por meio das obras do italiano que embasaremos nosso estudo acerca da entrada do imigrante chinês no Brasil.

Na década de 1880 , outras fontes da imprensa também passaram a se encarregar de propagar ideias contrárias à vinda do imigrante chinês, como, por exemplo, o periódico Jornal dos Economistas, produzido por profissionais liberais que se autodenominavam economistas.

\section{Angelo Agostini e algumas ilustrações}

O objeto de estudo do presente trabalho se foca no uso de imagens para a compreensão do processo histórico. Nesse caso, as imagens são as charges, que, segundo Rozinaldo Miani, têm a capacidade de expressar, por meio de desenhos, a opinião do autor, sem que esse precise dissertar sobre a sua posição ou ideias.

[...] a charge é uma representação humorística de caráter eminentemente político que satiriza um fato ou indivíduo específicos; ela é a revelação e defesa de uma idéia, portanto de natureza dissertativa, traduzida a partir dos recursos e da técnica da ilustração. [...] A charge deve ser reconhecida como uma espécie de 'editorial gráfico' (MIANI, 2005, p. 25).

Segundo Romualdo (2000, p. 6-71), as charges são elementos que carregam humor, mas não estão desvinculadas das problemáticas que cercam as suas publicações. Elas tentam reproduzir um tema de importância que está circulando, não apenas nos meios editoriais, mas dentro de uma sociedade ou grupo.

As charges acabam estimulando a leitura de todo o impresso para que sejam compreendidas, mas nem sempre expressam a mesma opinião que todo o material traz, pois também possuem autonomia temática.

Portanto, a produção de imagens que se baseiam na realidade é um elemento com grande potencial para a reconstrução histórica de um período ou tema. Aqui, serão analisadas como chave para a compreensão do modo como Angelo Agostini se posicionava sobre a imigração chinesa.

Como conteúdo para seus desenhos, Angelo Agostini utilizou-se do desastre econômico que o Brasil enfrentaria, caso continuasse com suas ideias de entrada dos chineses, usando como embasamento explicativo o fato de que esse povo iria prejudicar a oportunidade do liberto de se reassentar, tornando-se um pequeno proprietário, pois o seu custo era bem menor. 
Embora esse discurso pareça proteger os nacionais, há, na verdade, uma conclamação para que os europeus voltassem a ser o foco de imigrante ideal (DE PINHO BARREIROS, 2016, p. 99-100), mesmo que fosse mais caro e que dificultasse ainda mais a possibilidade de o liberto se estabelecer.

Logo após o fim do Congresso, Agostini trouxe à tona as suas caricaturas sobre os alvos da grande polêmica tratada na conferência.

Observemos a figura da Revista Illustrada de julho de 1878 (n.120, p. 8):

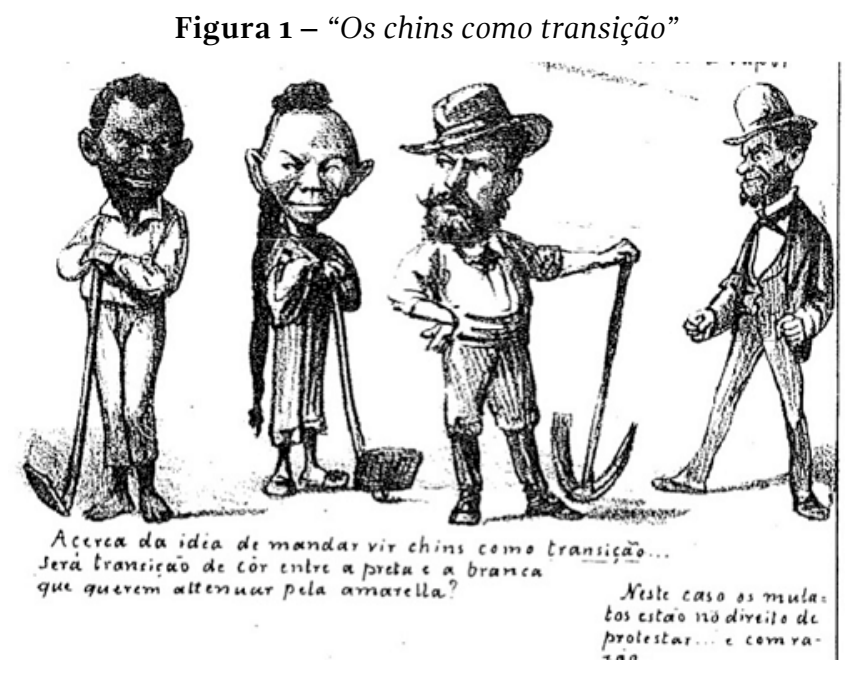

Fonte: Reprodução de AGOSTINI, 1878/IEB-USP.

Nesta imagem, enfatiza-se a figura do elemento asiático como meio de branqueamento. Pode-se perceber que há um negro, um chinês e um branco. Os olhares do amarelo e do branco unem-se àquele de cor escura, tendo como legenda a seguinte frase: "Acerca da ideia de mandar vir chins como transição... Será transição de cor entre a preta e a branca que querem atenuar pela amarella?"

O sentido dúbio da frase nos remete à elaboração de duas suposições: a primeira seria a de que o amarelo estaria mais próximo do branco, então deveria ser ele o responsável pela miscigenação; e a segunda hipótese, de que a palavra transição, grifada no desenho, daria a entender que, quando os chineses chegassem às terras brasileiras, eles seriam um novo tipo de escravo, vinculado a uma instituição muito semelhante àquela já encontrada no País.

De acordo com a obra de Rogério Dezem, Nabuco não concordava com a ideia de transição somente pela troca da cor do trabalhador, pois a mudança transformaria o escravo em trabalhador livre (DEZEM, 2005, p. 92).

Aparentemente, Angelo colocava em prática esses ideais mesmo dizendo que não se vinculava a fatores sociais que pudessem influenciar seus trabalhos.

Isso pois, vemos que, apesar de se considerar neutro, há uma ligação entre as pretensões do artista com as charges estampadas de sua autoria, nas quais os grandes proprietários são constantemente atacados por suas provocações a favor da mão de obra livre e assalariada.

Voltando à questão do Congresso Agrícola, e seus debates de grandes fazendeiros e decisões sobre o melhor tipo de mão de obra a se trazer para o Brasil, começamos a perceber que, apesar de seus preceitos de liberdade e fraternidade, e de seu trabalho não ser relacionado e 
nem influenciado por posicionamentos pessoais (mesmo que, em algumas de suas obras, o negro apareça em sofrimento, ressalvando ainda mais seu aval de abolicionista), a sua sátira denuncia o posicionamento dos fazendeiros e das pessoas de grande destaque.

Na imagem que será apresentada abaixo, podemos ver o desenho de duas grandes cabeças, uma retratada como um negro e a outra, um chinês. Sobre os desenhos das cabeças, grandes e desproporcionais, temos a figura de um homem sentado sobre elas. O detalhe que nos chama atenção é o fato de que este homem parece ser um homem branco, descendente de povos europeus, e, aparentemente, controla e direciona as duas cabeças.

Nossa interpretação pode eleger, como síntese da imagem, a problemática da mão de obra brasileira no período de transição do trabalho escravo para o livre. Neste sentido, o homem branco, vestido como um elemento importante, será o definidor dos destinos da raça negra e asiática, como se a estes sobrassem apenas a opção de ser o trabalhador do País, sem nenhuma ideia de progresso social e/ou econômico.

Em continuidade, podemos perceber que os personagens negro e asiático se entreolham, denotando certa rivalidade, propondo, ao observador, que ser o escolhido para um novo tipo de trabalho, muito semelhante à escravidão, lhes é de extrema importância.

Ao observarmos a legenda da imagem, que diz "Preto e Amarello, é possível que haja quem entenda que a nossa lavoura só pode ser sustentada por essas duas raças tão feias! Mau gosto!”, vemos o reflexo das conversações que ocorriam dentro do Congresso Agrícola, que falavam que a mão de obra tão almejada era a do homem branco, o europeu, aquele que traria o dinamismo para a sociedade brasileira, na qual os brancos também poderiam sustentar-se sob o trabalho do negro e do amarelo.

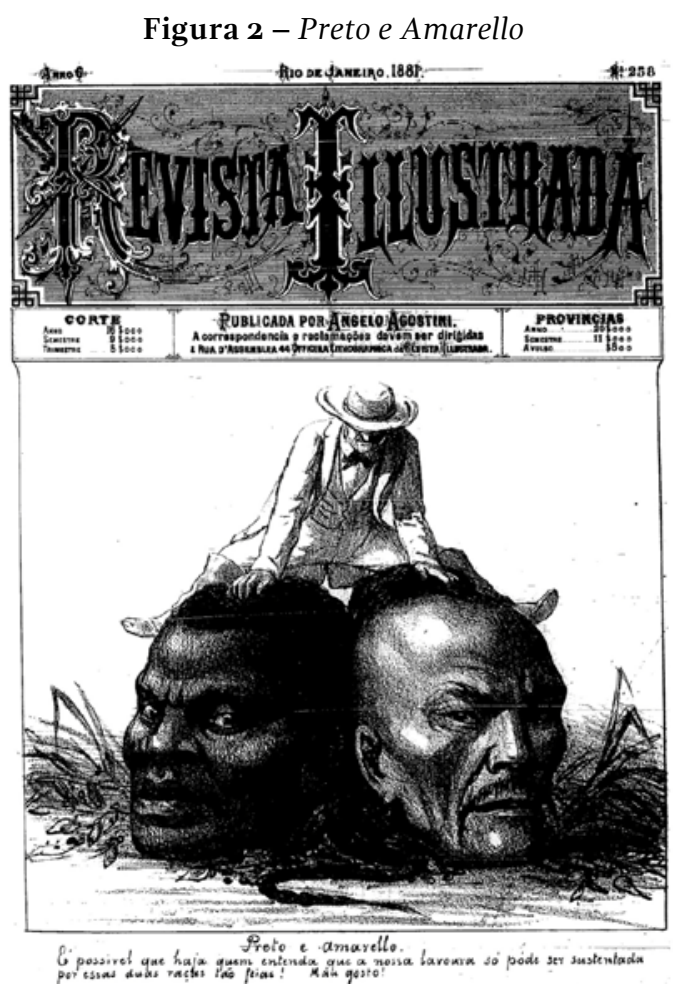

Fonte: Reprodução de AGOSTINI, 1881/IEB-USP 
A Revista Illustrada era um dos meios mais acessíveis para a divulgação de acontecimentos políticos, tanto que o próprio Monteiro Lobato chegou a afirmar que: “Disso resultou termos na coleção da Revista Illustrada um documento histórico retrospectivo cujo valor sempre crescerá com o tempo- tal qual aconteceu com os desenhos de Debret e Rugendas" (LIMA, 1963, p. 117-20).

Após discussões dentro do que envolve a "Questão Chinesa”, em 1879, uma coleção de textos sobre as desvantagens do chin no Brasil foi editada pela Casa Garraux de São Paulo. Essa obra, intitulada Reflexões sobre a Colonisação no Brazil, reuniu o posicionamento de importantes autores que versavam sobre a terra. Outros textos também creditavam, ao oriental, adjetivos da pior qualidade, além de racializar pejorativamente o amarelo, ajudando na criação de um mito.

Abaixo, tem-se a uma charge na qual o trabalho do autor fora embebido de ideias irreais sobre o chin:

Figura 3 - "A questão chinesa"

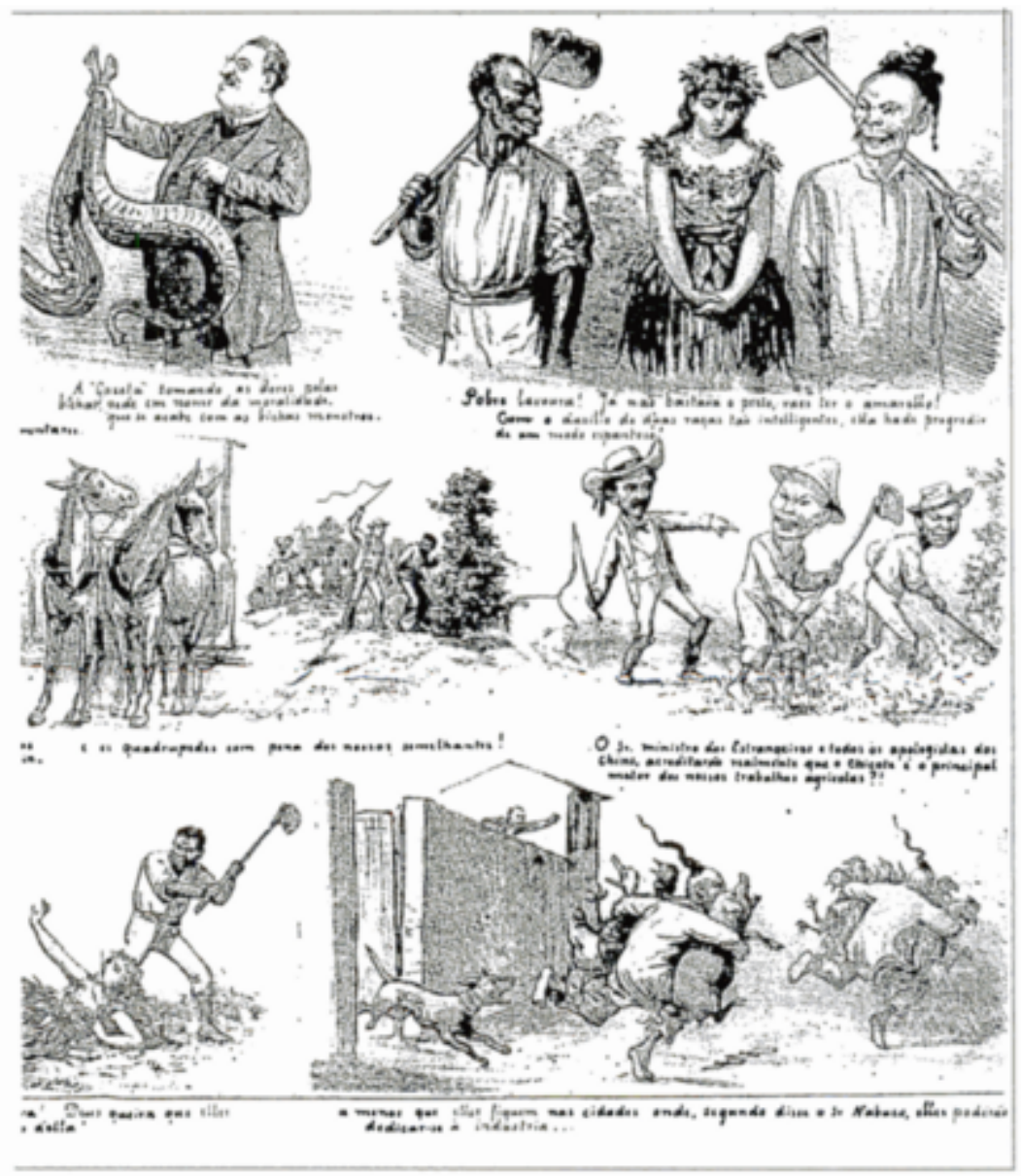

Fonte: Reprodução de AGOSTINI,1879, IEB/USP

Na sátira acima há uma série de desenhos, mas nos focaremos em apenas dois deles: o primeiro, que mostra um negro, uma jovem vestida de roupas que lembram folhas, e um chinês, tendo as duas figuras masculinas olhando para a jovem que parece entristecida. É possível entender, nessa imagem, que a moça, representando a lavoura nacional, está triste pois suas únicas opções de trabalho são as raças tidas como inferiores, não deixando alternativas frente à crise por mão de obra que o País se encontrava. 
O segundo desenho, por sua vez, encontra-se no canto inferior, e é a imagem de dois chineses, identificados pelas duas tranças, correndo com animais nas mãos, e a seguinte frase na legenda: "a menos que elles fiquem nas cidades onde, disse o senhor Nabuco, elles poderão dedicar-se a Indústria além de um verdadeiro empurra mostrado na frase acima, onde a lavoura não quer e tenta os jogar para a indústria”. Essa gravura agrava o preconceito contra o amarelo, que além de viciado em ópio, fora promovido a ladrão.

Segundo o historiador da Arte, E. Gombrich (1999, p. 139), é nesse universo criador que o chargista se torna responsável pela união de fatos descoordenados, ou não conhecidos, em uma imagem inventada, o que parece ser o caso do italiano, que colocava as suas impressões pessoais em sua produção.

Mas não foi apenas Agostini que deixou as suas impressões sobre o chinês no Brasil. Charles Ribeyrolles, jornalista e político francês, não deixou a sua posição, em relação às discussões sobre a vida ou não dos chineses, passar em branco, como podemos acompanhar no trecho a seguir:

Espera-se colonizar com os chineses, os coolies, os malaios e todas essas raças degeneradas do oriente, sorte de lepra humana? Já se experimentou a espécie do Celeste Império. Que produziu ela? O Brasil, de resto, já está farto dessas famílias mescladas e bastardas que não constituem um povo. O que lhe falta é sangue, a atividade, a ciência da Europa (RIBEYROLLES, 1980, v. 2, p. 148).

Nesse entender, tem-se a imagem abaixo, a qual deixa claro ao leitor a ideia de que o chinês, colocado em destaque, espera ansiosamente pela dominação das terras brasileiras.

Nesse sentido, há a possibilidade de duas interpretações consequentes: a vinda massiva dos imigrantes do Império Celeste, e/ou a mistura das raças, tão trabalhada por Gobineau, em seu Ensaio sobre as desigualdades das raças humanas (1853).

Figura 4 - "O novo Sol"

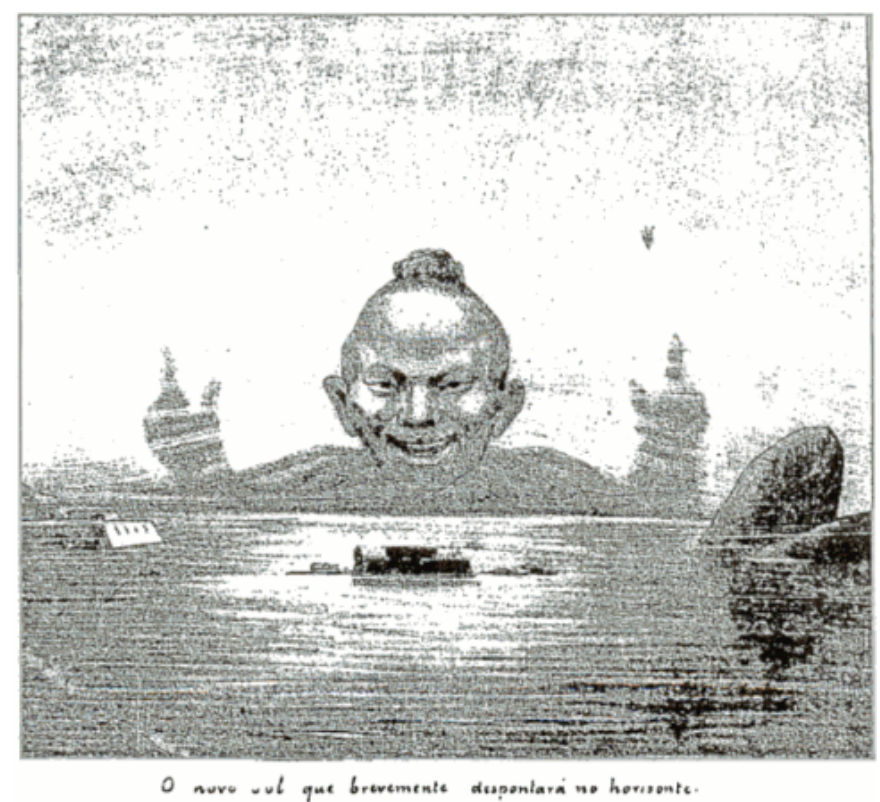

Fonte: Reprodução de AGOSTINI, 1879, IEB/USP. 
Seguindo a lógica do abolicionista, a mão de obra que deveria ser usada com o fim do trabalho escravo teria de ser a do recém-liberto ou do mulato, mas jamais trazer novos trabalhadores para o País.

Ao pensarmos nisso, não deixamos de questionar a posição do dono da Revista Illustrada, uma vez que, devido as suas publicações e o seu viés abolicionista, pode nos levar a entender que ele é contra a entrada dos chins.

Talvez por isso, a caricatura do imigrante chinês seja motivo de piada, diferentemente de como era retratado o negro, que, em várias de suas cenas, é mostrado com certa sensibilidade.

\section{Considerações Finais}

Diante do exposto, é evidente a importância de Angelo Agostini, e da sua produção artística, como elemento participativo nas produções impressas do século XIX brasileiro.

Fazendo um levantamento de suas obras, constata-se que, sua maior parte, teve a defesa dos negros como base, em um caráter abolicionista. Porém, seus trabalhos não se limitaram a defender a causa, atuando, igualmente, como informativo para todos aqueles que tinham acesso as suas publicações.

O brilhantismo de seu trabalho, entretanto, não se circunda apenas à temática abolicionista, utilizando suas sátiras para denunciar um possível nascimento de outro tipo de semiescravidão. Talvez por essa razão, o artista italiano demonstre um certo desapreço ao considerar a entrada do asiático, entendida, muitas vezes, como motivo de piada.

Portanto, analisar suas obras e ligá-las ao quadro político que se alastrava pela imprensa dos finais do século XIX também nos leva a pensar que Angelo não estava apenas poupando o negro dos maus tratos que aqui sofreu, mas também poupando outras raças de tão cruel destino, envolvendo seus leitores em uma luta que nos convida a pensar sobre o que realmente se queria no País: brancos ou uma espécie de cativo com pouquíssimos diretos? O último, parecia ser o mais provável.

Com caráter transitório, o chin chegara ao Brasil, e aos dissabores do solo subtropical do País, encontraram um triste fim para grande parte dos quase três mil que por aqui apartaram sem o cumprimento das promessas de regresso à China.

\section{Referências}

AGOSTINI, Ângelo. Preto e Amarello. Revista Illustrada, Rio de Janeiro, n. 258, jul. 1881. AGOSTINI, Ângelo. A questão chinesa (cont.). Revista Illustrada, Rio de Janeiro, n.175, 1879, p.5. AGOSTINI, Ângelo. O novo sol. Revista Illustrada, Rio de Janeiro, n. 154, 1879, Capa, IEB-USP, apud DEZEM, R. Matizes do "amarelo": a gênese dos discursos sobre os orientais no Brasil (1878-1908). São Paulo: Associação Editorial Humanitas, 2005.

AGOSTINI, Ângelo. Os chins como transição. Revista Illustrada, Rio de Janeiro, n. 120, 1878. p. 8. IEB-USB, apud DEZEM, R. Matizes do "amarelo": a gênese dos discursos sobre os orientais no Brasil (1878-1908). São Paulo: Associação Editorial Humanitas, 2005. 
AGOSTINI, Ângelo. Preto e Amarello. Revista Illustrada. n. 258, Rio de Janeiro, 1881, Capa, IEB-USP, apud DEZEM, R. Matizes do "amarelo": a gênese dos discursos sobre os orientais no Brasil (1878-1908). São Paulo: Associação Editorial Humanitas, 2005.

AZEVEDO, Celia M. M. de. Onda negra, medo branco: o negro no imaginário das elites, século XIX. São Paulo: Annablume, 1987.

BALABAN, Marcelo. Poeta do lápis: a trajetória de Angelo Agostini no Brasil Imperial - São Paulo e Rio de Janeiro 1864-1888. Tese (Doutorado em História) - IFCH, UNICAMP, Campinas, 2005.

BALABAN, Marcelo. Poeta do lápis: sátira e política na trajetória de Angelo Agostini no Brasil Imperial(1864-1888). Campinas, SP: Editora da Unicamp.

BASSETTO, Sylvia. Política de mão-de-obra na economia cafeeira do oeste paulista (período de transição). Tese de Doutoramento. São Paulo, FFLCH/USP, 1982.

BeIguelman, Paula. O Encaminhamento Político do Problema da Escravidão no Império. In: Holanda, Sergio Buarque de. (coord.). História Geral da Civilização Brasileira - O Brasil Monárquico: reações e transações, Tomo II, $5^{\circ}$ Volume. Rio de Janeiro: Bertrand Brasil, 2004. CONGRESSO AGRÍCOLA: edição fac-similar dos anais do Congresso Agrícola, realizado no Rio de Janeiro em 1878. Introdução e notas de José Murilo de Carvalho. Rio de Janeiro: Fundação Casa de Rui Barbosa, 1988.

CONRAD, Robert. Os Últimos anos da escravatura no Brasil: 1850-1888. Rio de Janeiro: Civilização Brasileira, 1975 .

CONRAD, Robert. The planter class and the debate over chinese immigration to Brazil, 1850-1893. International Migration Review. Nova York, v. IX, n. 1, 1975. https://doi.org/10.2307/3002529

COSTA, Emília Viotti da. Da senzala à colônia. 3. ed. São Paulo: Editora UNESP, 1998.

DEMONSTRAÇÃO das conveniencias e vantagens á lavoura no Brasil pela introdução dos trabalhadores asiaticos da China. Rio de Janeiro: Typographia de P. Braga \& C,1877.

DE PINHO BARREIROS, Daniel. O fracasso do trabalho assalariado na agricultura fluminense: diplomacia, capitalismo e a imigração asiática (década de 1890). História Econômica \& História de Empresas, v. 19, n. 1, 2016. https://doi.org/10.29182/hehe.v19i1.396

DEZEM, R. Matizes do "amarelo": a gênese dos discursos sobre os orientais no Brasil (1878-1908). São Paulo: Associação Editorial Humanitas, 2005.

DO LAGO, Luiz Aranha Corrêa. Da escravidão ao trabalho livre-Brasil, 1550-19oo. Editora Companhia das Letras, 2014.

Don Quixote, Rio de Janeiro, n. 163, ano IX, p. 2-3, 15 set. 1903.

DRESCHER, Seymour. A abolição brasileira em perspectiva comparativa. História Social, n. 2, p. 115-162, 1995 .

DRESCHER, Seymour. Abolição: uma história da escravidão e do antiescravismo. Tradução de Antonio Penalves Rocha. São Paulo: Editora Unesp, 2011.

ELIAS, Maria José. Os debates sobre o trabalho dos chins e o problema da mão de obra no Brasil durante o século XIX. In: DE PAULA, Eurípedes Simões. Trabalho livre e trabalho escravo: anais do VI Simpósio Nacional dos Professôres Universitários de História. 1973.

ELIAS, Maria José. Introdução ao estudo da imigração chinesa. Anais do Museu Paulista. São Paulo, t. XXIV, 1970. 
ELTIS, David. Economic Growth and the Ending of the Transatlantic Slave Trade (Nova York, 1987), apêndice A.

GOMBRICH, E.H. Meditações sobre um cavalinho de pau. E outros ensaios sobre teoria da arte. São Paulo: Edusp, 1999.

GONÇALVES, Paulo C. Mercadores de Braços: riqueza e acumulação na organização da emigração europeia para o Novo Mundo. 1. ed. São Paulo: Alameda Casa Editorial / FAPESP, 2012.

GONÇALVES, Paulo C. Entre o escravo e o trabalhador livre: o tráfico de mão-de-obra no Atlântico-sul e Caribe em meados do oitocentos. In: XXVI SIMPÓSIO NACIONAL DE HISTÓRIA: ANPUH 50 Anos, 2011, São Paulo. v. 1. Anais do [...], ANPUH, 2011.

IOTTI, Luiza Horn. Imigração e Colonização: legislação de 1747 a 1915. Caxias do Sul: EDUCS, 2001.

LESSER, Jeffrey. A negociação da identidade nacional: Imigrantes, minorias e a luta pela etnicidade no Brasil. São Paulo: Editora da Unesp. 2001.

LESSER, Jeffrey. A invenção da brasilidade: identidade nacional, etnicidade e políticas de imigração, São Paulo, Editora Unesp, 2015.

LIMA, Herman. História da caricatura no Brasil. J. Olympio Editôra, 1963.

LIMA, José Custódio de Azevedo. EUA Brasil Imigração Chinesa. São Paulo: Typographia a vapor de Jorge Seckler\& C. 1886.

LIMA, Silvio Cezar de Souza. Determinismo biológico e imigração chinesa em Nicolau Moreira (1870-1890). Dissertação (Mestrado em História das Ciências e da Saúde) - Casa de Oswaldo Cruz/Fiocruz, Rio de Janeiro, 2005.123 p.

MENDONÇA, Salvador de. Trabalhadores Asiaticos. New York: Typographia do “Novo Mundo”, 1879.

MIANI, Rozinaldo Antonio. As transformações no mundo do trabalho na década de 1990: o olhar atento da charge na imprensa do Sindicato dos Metalúrgicos do ABC paulista. 2005. Tese (Doutorado em História) - Universidade Estadual Paulista, Assis, 2005.

NARO, Nancy Priscilla Smith. Revision and persistence: recent historiography on the transition from slave to free labour in rural Brazil. London: Frank class, Slavery and Abolition, 13, 1992. https://doi.org/10.1080/01440399208575066

NOVAIS, Fernando; MOTTA, Carlos Guilherme. A Independência política do Brasil. São Paulo: Hucitec, 1996.

NOVAIS, Fernando. As Dimensões da Independência. In: MOTA, Carlos Guilherme. 1822: Dimensões, São Paulo: Editora Perspectiva, 1972.

PINHEIRO. João Pedro Xavier. Importação de trabalhadores chins. Memória apresentada ao ministério da agricultura, Commercio e obras publicas e impressa em sua ordem. Rio de janeiro, typographia de João Ignácio da Silva,1869.

RIBEYROLLES, Charles. O Brasil pitoresco. Belo Horizonte/São Paulo: Itatiaia/Edusp, 1980.

ROMUALDO, Edson Carlos. Charge jornalística: intertextualidade e polifonia: um estudo de charges da Folha de S. Paulo. Maringá: EDUEM, 2000.

SCHWARCZ, Lilia Moritz. O espetáculo das raças: cientistas, instituições e questão racial no Brasil. São Paulo: Companhia das Letras, 1993. 
SKIDMORE, Thomas E. Preto no branco: raça e nacionalidade no pensamento brasileiro. Paz e Terra, 1976.

SOUZA. J. Cardoso de Menezes. Theses sobre a colonização do Brasil. Projecto de solução ás questões sociaes, que se prendem a este difícil problema. Rio de Janeiro: Typographia Nacional, 1875. WERNECK, L. P. de L. Ideias sobre a colonização precedidas de uma succinta exposição dos principiosgeraes que regem a população. Rio de Janeiro: Typographia Universal de Laemert, 1855.

ZANETTI, V.; PAPALI, M. A.; DEL OLMO, M. J. A. Os Últimos Anos da Escravatura no Brasil: Uma Análise da Contribuição Historiográfica de Robert Conrad. Revista do Mestrado de História, v. 10, n. 1, p. 51-84, 2015.

Recebido em: 7/12/2017.

Aprovado em: 2/4/2018.

\section{Maysa Silva Oliveira}

Mestra em história/UNESP - Assis.

Maysa web@hotmail.com

ORCID: http://orcid.org/0000-0002-5985-7223

Instituição: Universidade Estadual Paulista Júlio de Mesquita Filho - UNESP

Endereço postal: Av. Dom Antônio, 2100 - Parque Universitario, Assis - SP, 19806-900, Brasil 